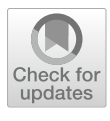

Cite as

Nano-Micro Lett.

(2022) 14:8

Received: 11 July 2021

Accepted: 23 August 2021

Published online: 2 December 2021

(C) The Author(s) 2021

\section{A Novel Artificial Neuron-Like Gas Sensor Constructed from CuS Quantum Dots/Bi $\mathbf{B}_{3}$ Nanosheets}

\author{
Xinwei Chen ${ }^{1}$, Tao Wang ${ }^{1}$, Jia Shi ${ }^{1}$, Wen Lv ${ }^{1}$, Yutong Han ${ }^{1}$, Min Zeng ${ }^{1}$, Jianhua Yang ${ }^{1}$, \\ Nantao $\mathrm{Hu}^{1}$, Yanjie $\mathrm{Su}^{1}$, Hao Wei ${ }^{1}$, Zhihua Zhou ${ }^{1}$, Zhi Yang ${ }^{1}$, Yafei Zhang ${ }^{1}$,
}

\title{
HIGHLIGHTS
}

- An ultra-sensitive capture of $\mathrm{NO}_{2}$ molecules and fast charge collection and transfer has been realized by constructing the model of artificial neuron-likegas sensing structure based on $\mathrm{CuS}$ quantum dots (QDs)/ $\mathrm{Bi}_{2} \mathrm{~S}_{3}$ nanosheets (NSs)realizes.

- Simulation analysis revealed that $\mathrm{CuS}$ QDs and $\mathrm{Bi}_{2} \mathrm{~S}_{3} \mathrm{NSs}$ can be used, respectively, as the main adsorption sites and charge transport pathways, thus leading to a greatly enhanced gas capture ability and charge conduction performance of $\mathrm{NO}_{2}$.

\begin{abstract}
Real-time rapid detection of toxic gases at room temperature is particularly important for public health and environmental monitoring. Gas sensors based on conventional bulk materials often suffer from their poor surface-sensitive sites, leading to a very low gas adsorption ability. Moreover, the charge transportation efficiency is usually inhibited by the low defect density of surface-sensitive area than that in the interior. In this work, a gas sensing structure model based on $\mathrm{CuS}$ quantum dots $/ \mathrm{Bi}_{2} \mathrm{~S}_{3}$ nanosheets ( $\mathrm{CuS}$ QDs/ $\mathrm{Bi}_{2} \mathrm{~S}_{3} \mathrm{NSs}$ ) inspired by artificial neuron network is constructed. Simulation analysis by density functional calculation revealed that $\mathrm{CuS}$ QDs and $\mathrm{Bi}_{2} \mathrm{~S}_{3}$ NSs can be used as the main adsorption sites and charge transport pathways, respectively. Thus, the high-sensitivity sensing of $\mathrm{NO}_{2}$ can be realized by designing the artificial neuron-like sensor. The experimental results showed that the CuS QDs with a size of about $8 \mathrm{~nm}$ are highly adsorbable, which can enhance the $\mathrm{NO}_{2}$ sensitivity due to the
\end{abstract}

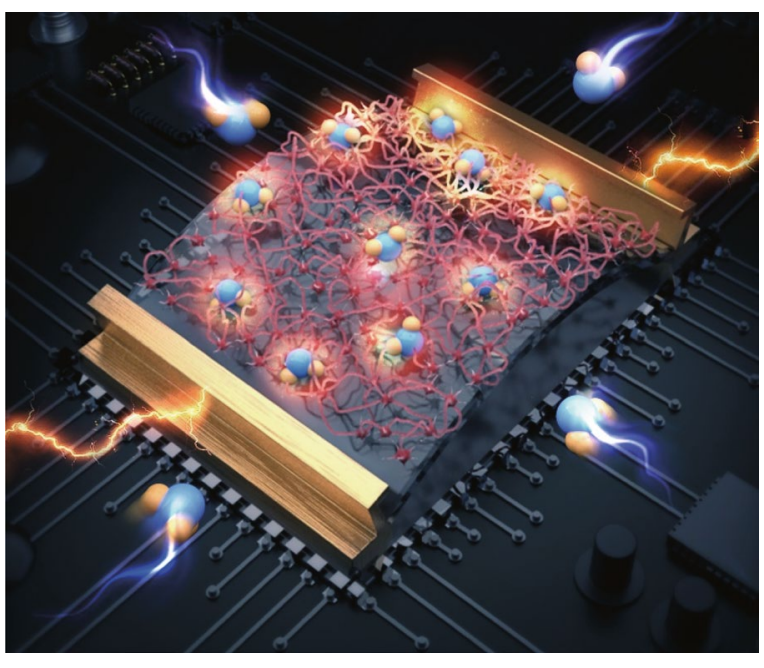
rich sensitive sites and quantum size effect. The $\mathrm{Bi}_{2} \mathrm{~S}_{3}$ NSs can be used as a charge transfer network channel to achieve efficient charge collection and transmission. The neuron-like sensor that simulates biological smell shows a significantly enhanced response value (3.4), excellent responsiveness (18 s) and recovery rate (338 s), low theoretical detection limit of $78 \mathrm{ppb}$, and excellent selectivity for $\mathrm{NO}_{2}$. Furthermore, the developed wearable device can also realize the visual detection of $\mathrm{NO}_{2}$ through real-time signal changes.

KEYWORDS Artificial neuron-like gas sensor; Heterostructure design; Nitrogen dioxide detection; Wearable device

Zhi Yang, zhiyang@sjtu.edu.cn; Yafei Zhang, yfzhang@sjtu.edu.cn

1 Key Laboratory of Thin Film and Microfabrication (Ministry of Education), Department of Micro/Nano Electronics, School of Electronic

Information and Electrical Engineering, Shanghai Jiao Tong University, Shanghai 200240, People's Republic of China 


\section{Introduction}

Over the last decades, the gradual development of industrialization and urbanization leads to the deterioration of environmental quality, especially the air condition [1, 2]. In order to cope with the timely detection of toxic and hazardous gases and to prevent the related diagnosis of respiratory injuries and diseases, the active development of low-cost, durable, high-performance gas sensors has become the focus of current research $[3,4]$. With the development of the "Internet of Things" and artificial neural networks, the design of wearable gas sensors provides a promising strategy to broaden the practical applications by combining real-time monitoring and big data analysis, which allows the device applicable to the early detection of any health hazards [5-8]. Therefore, exploring wearable devices with improved room temperature detection ability ranks as the key to expand the field of gas sensing.

Similarities between biological structures and artificial neural-like networks have inspired the development of neuron-based mechanical sensing and optical sensing [9-11]. The olfactory neurons that exist in the olfactory bulb of higher animals play a key role in extracting olfactory signals through gas sensing [12]. When the human body's olfactory receptors receive a certain intensity of stimulation, it will cause changes in the cell membrane surface potential to trigger action potentials, convert chemical signals into electrical signals, and conduct signal analysis along the nerve fibers to the central system. A large number of olfactory sensory neurons and rapid potential changes are essential for high spiritual sensitivity. Inspired by this, it is very meaningful to construct an artificial neuron-like sensor model that is different from traditional bulk sensitive materials and contains a large number of adsorption sites and fast charge transport channels.

Among active sensing materials for artificial neurons, binary or heterogeneous structures constructed from twodimensional (2D) materials can achieve rapid response, which is of great significance for room temperature wearable sensing in practical applications. Bismuth sulfide $\left(\mathrm{Bi}_{2} \mathrm{~S}_{3}\right)$ with the direct bandgap of $1.3 \mathrm{eV}$, high carrier mobility, and excellent environment-friendly characteristics received potential attention in sensing applications [13, 14]. As a member of the stibnite family, the layered structure of $\mathrm{Bi}_{2} \mathrm{~S}_{3}$ is projected along the $b$-axis direction by atomic-scale ribbons, which are fixed together by van der Waals (vdW) forces. Bulk $\mathrm{Bi}_{2} \mathrm{~S}_{3}$ can be separated into two-dimensional (2D) layer structures along the (010) crystal facets maintained by weak vdW forces $[15,16]$. Unfortunately, like other similar 2D gas-sensitive materials, 2D-layered $\mathrm{Bi}_{2} \mathrm{~S}_{3}$ exhibits poor recovery properties at room temperature, which severely limits its widespread applications $[17,18]$. In addition, recent studies have also proved that $\mathrm{CuS}$ as a p-type semiconductor material can be used alone or as a second-phase modifier to achieve rapid detection of trace gases at room temperature $[19,20]$. Therefore, modifying the surface of $2 \mathrm{D} \mathrm{Bi}_{2} \mathrm{~S}_{3}$ nanosheets (NSs)with OD $\mathrm{CuS}$ quantum dots (QDs) can realize the scattered construction of sensitive points on the neuron-like network and develop a neuron-like olfactory system that is different from the traditional inefficient adsorption detection-type sensors. This will effectively help to achieve rapid and sensitive detection at room temperature.

Herein, we first report a sensor model inspired by the biological olfactory neuron system, which realizes the efficient detection of $\mathrm{NO}_{2}$ by uniformly loading $\mathrm{CuS}$ QDs on $\mathrm{Bi}_{2} \mathrm{~S}_{3}$ NSs. Density functional theory (DFT) reveals the charge distribution and transfer process of 0D-2D heterojunction neurons before and after contacting gas molecules. As a result, the 0D p-type $\mathrm{CuS}$ quantum dots with higher adsorption energy for $\mathrm{NO}_{2}$ molecules are confirmed to be the main adsorption sites for the target gas, and the $2 \mathrm{D}$ n-type $\mathrm{Bi}_{2} \mathrm{~S}_{3}$ nanosheets provide the main transfer path for the charge carriers. Subsequent experiments confirmed that appropriately high-tuned OD QDs were loaded on the carrier as secondphase particles. Attribute to the numerous active adsorption sites and a large amount of charge transfer, interface electronic interaction can be greatly enhanced, which facilitates the action of gas molecules on the material surface [21, 22]. Moreover, the design of this $n-p$ heterojunction can effectively increase the rate of charge transfer and has realized the ultra-sensitive response of artificial neurons to the stimulation of gas molecules. Therefore, this study uses the synergistic effect between high adsorption energy and fast charge transfer to simulate the biological olfactory detection process by rationally constructing heterojunction neurons and further realizes the sensitive monitoring of $\mathrm{NO}_{2}$. Finally, the sensing materials have been further integrated into our self-developed wearable gas detection equipment. The realtime display and cloud storage of detection signals on smart 
device applications through data collection and Bluetooth wireless transmission has been fully achieved. Our work sheds light on the rational design of bio-simulation intelligence, wearable, and wireless sensing equipment toward the "neuron-like sensitive intelligence era."

\section{Experimental Section}

\subsection{Synthesis of $\mathrm{Bi}_{2} \mathrm{~S}_{3} \mathrm{NSs}$}

$30 \mathrm{mg}$ of commercial bulk $\mathrm{Bi}_{2} \mathrm{~S}_{3}$ powder was added to a $25 \mathrm{~mL}$ flask. $10 \mathrm{~mL}$ of aqueous ethanol in various volume ratios was added as a dispersion solvent. Ultrasonication was performed for $8 \mathrm{~h}$. Then, the precipitate was removed by centrifugation treatment.

$100 \mathrm{mg}$ of $\mathrm{Bi}_{2} \mathrm{~S}_{3}$ powder and acetonitrile was ground with agate mortar for $2 \mathrm{~h}$ [23]. The samples were dried with a vacuum oven and then redistribute in a ethanol aqueous solution (70 vol\%, $50 \mathrm{~mL}$, Fig. S1). After ultrasonic treatment at $200 \mathrm{~W}$ for $3 \mathrm{~h}$, the supernatant was extracted by centrifugation at $1500 \mathrm{rpm}$ for $20 \mathrm{~min}$ to collect $\mathrm{Bi}_{2} \mathrm{~S}_{3} \mathrm{NSs}$ $[17,24]$.

\subsection{Synthesis of CuS QDs/Bi $\mathrm{B}_{2} \mathrm{~S}_{3} \mathrm{NSs}$ and $\mathrm{CuS}$}

$0.0138 \mathrm{~g}$ of $\mathrm{Cu}\left(\mathrm{NO}_{3}\right)_{2}$ and $0.01 \mathrm{~g}$ of $\mathrm{Na}_{2} \mathrm{~S} \bullet 9 \mathrm{H}_{2} \mathrm{O}$ were dissolved in $20 \mathrm{~mL}$ of ethanol aqueous solution, respectively. Then, $0.1 \mathrm{~g} \mathrm{Bi}_{2} \mathrm{~S}_{3} \mathrm{NSs}$ were dispersed in $10 \mathrm{~mL}$ ethanol and stirred continuously with an ultrasonic instrument for $30 \mathrm{~min}$. The dispersion was mixed with the above two solutions, respectively, for reaction, and finally, the prepared $\mathrm{CuS}$ QDs $/ \mathrm{Bi}_{2} \mathrm{~S}_{3}$ NSs were collected after centrifugation and washing [22]. Following the same procedure as above, bare $\mathrm{CuS}$ was obtained with the addition of only $\mathrm{Cu}\left(\mathrm{NO}_{3}\right)_{2}$ and $\mathrm{Na}_{2} \mathrm{~S} \bullet 9 \mathrm{H}_{2} \mathrm{O}$. The as-prepared products were named as BC-2.5, BC-3, BC-4, BC-5, BC-6, BC-7.5, BC-10, and BC-20 corresponding to $2.5,3,4,5,6,7.5,10$, and $20 \mathrm{wt} \%$ of $\mathrm{CuS}$, respectively.

\subsection{Sensor Device Fabrication and Sensing Measurements}

The sensor device uses a flexible electrode sputtered with Au fingers on polyimide (PI) substrate. Clean the electrode surface alternately with deionized water and ethanol to promote the contact between the sensing membrane and the electrode. To fabricate the gas sensor, the ethanol dispersion of $\mathrm{CuS}$ QDs $/ \mathrm{Bi}_{2} \mathrm{~S}_{3} \mathrm{NSs}$ with a concentration of 70 vol\% was sprayed onto the PI electrode using inkjet printing equipment. Finally, the as-prepared sensors were dried in the vacuum oven.

The details of the gas-sensitive test system can be found in our previous paper [25]. In simple terms, the chamber was purged with dry compressed air before the measurement to stabilize the baseline signal. Subsequently, the mass flow controller (MFC) was used to control the flow of $\mathrm{NO}_{2}$ and dry compressed air with an initial concentration to obtain $\mathrm{NO}_{2}$ dilution gas of different concentrations with a flow rate of 1 standard liter/min (SLM). The Agilent 4156C analyzer was utilized to detect current changes of gas sensors at room temperature $\left(25^{\circ} \mathrm{C}\right)$. The response value is defined as $R_{\mathrm{a}} / R_{\mathrm{g}}$, which are resistances of the sensor when exposed to compressed air and $\mathrm{NO}_{2}$, respectively. In addition, the response and recovery time ( $\tau_{\text {res }}$ and $\left.\tau_{\text {rec }}\right)$ are the time required for the sensor to fully respond and recover to $90 \%$ after being exposed to $\mathrm{NO}_{2}$.

\subsection{Characterizations}

Crystallinity and morphology of as-prepared CuS QDs/ $\mathrm{Bi}_{2} \mathrm{~S}_{3} \mathrm{NSs}$ sample were analyzed with the X-ray diffractometry (XRD, D8 ADVANCE, Bruker), transmission electron microscopy (TEM, JEM-2100, JEOL, Japan), and scanning electron microscopy (SEM, Carl Zeiss Ultra Plus, Germany). The chemical components and band structures were studied by X-ray photoelectron spectroscopy and ultraviolet photoelectron spectroscopy (XPS and UPS, Kratos Axis Ultra $^{\text {DLD }}$ ). Ultraviolet-visible (UV-vis) absorption spectra (Perkin-Elmer, USA) were utilized to characterize bandgaps of materials. The Raman spectra were acquired on the confocal Raman microscope (RENISHAW, England). Mott-Schottky plots measurements were performed with an electrochemical workstation (CHI 760E, Shanghai Chenhua). 


\section{Results and Discussion}

\subsection{DFT Calculation of Neuron-like Sensor Network Inspired by Olfactory Sensory Neurons}

It is of great significance to deeply understand the perception process of the olfactory organs of organisms to odor molecules and to compare the mechanism of artificial neuron gas sensors with it. As shown in Fig. 1a, when the human body's olfactory receptors receive a certain intensity of stimulation, it will cause changes in the surface potential of the cell membrane to trigger action potentials, convert chemical signals into electrical signals, and conduct analysis along nerve fibers to the central system and generate corresponding reaction [12]. A large number of sensory neurons in the biological olfactory system can realize super-sensitivity to gas molecules, and the timely conduction of electric potentials realizes the rapid transmission of signals. Inspired by this, the $\mathrm{CuS}$ QDs/ $/ \mathrm{Bi}_{2} \mathrm{~S}_{3}$ NSs-based neuron-like sensing model constructed by loading the $0 \mathrm{D}$ adsorption sites on the $2 \mathrm{D}$ semiconductor transmission channel has great potential to realize highly sensitive sensing of $\mathrm{NO}_{2}$ molecules.

In order to reveal the role of artificial olfactory neuron sensing interface in the process of $\mathrm{NO}_{2}$ sensing, DFT was used to analyze the adsorption and charge transfer processes of $\mathrm{NO}_{2}$. Four binding structures of $\mathrm{NO}_{2}$ on $\mathrm{CuS}-\mathrm{Bi}_{2} \mathrm{~S}_{3}$ are studied in our work, and the adsorption conformation is shown in Fig. 1d-g. The corresponding binding energies $\left(E_{b}=E_{\mathrm{NO}_{2}}+E_{\mathrm{CuO}-\mathrm{Bi}_{2} \mathrm{~S}_{3}}-E_{\text {total }}\right)$ are 1.15, 1.70, 1.45, and $2.25 \mathrm{eV}$. The results showed that $\mathrm{NO}_{2}$ prefers to bind to $\mathrm{CuS}-\mathrm{Bi}_{2} \mathrm{~S}_{3}$ with forming $\mathrm{N}-\mathrm{Cu}$ bonds, and the type of Bi-O binding structure has the smallest binding energy, and the length of $\mathrm{M}(\mathrm{Bi} / \mathrm{Cu})-\mathrm{O}$ bond is listed in Table $\mathrm{S} 1$. To explain the difference of binding property, charge density difference, Bader charge transfer, and $\mathrm{M}-\mathrm{O}$ bond length are analyzed. Clearly, the binding structure with $\mathrm{Cu}-\mathrm{O}$ bond structure is favorable with the highest binding. As displayed in Fig. 1b, c and Table S2, for Bi-O structure, the charge is mainly transferred between $\mathrm{Bi}$ and $\mathrm{O}$ atoms, while for $\mathrm{Cu}-\mathrm{O}$, it is between $\mathrm{Cu}$ and $\mathrm{O}$ atoms. Bader charge analysis shows that $\mathrm{CuO}$ and $\mathrm{NO}_{2}$ have greater charge transfer, which may be beneficial to the binding of $\mathrm{NO}_{2}$, which is consistent with the relationship between adsorption energy. This series of DFT results proved the conclusion that OD CuS QDs are used as $\mathrm{NO}_{2}$ sensitive points, and $2 \mathrm{D} \mathrm{Bi}_{2} \mathrm{~S}_{3} \mathrm{NSs}$ are used as a charge transport network to achieve an efficient gas sensing response. Therefore, in the sensing process of artificial olfactory neurons, the $\mathrm{CuS}$ QDs/ $/ \mathrm{Bi}_{2} \mathrm{~S}_{3} \mathrm{NSs}$ heterostructure sensing unit can efficiently adsorb gas molecules and quickly transfer charge signals, which undoubtedly greatly improves the efficient sensing of $\mathrm{NO}_{2}$.

\section{2 $\mathrm{CuS} \mathrm{QDs} / \mathrm{Bi}_{2} \mathrm{~S}_{3} \mathrm{NSs}$-Based Sensor Inspired by Biological Olfactory Neurons}

Figure 2a shows the process of recognition and perception of the smell of the external environment by organisms. When the receptors located in the olfactory bulb of the human body are stimulated by a certain intensity of gas molecules, olfactory receptor cells release electrical signals. The electrical signal is then conducted in the olfactory glomerulus and finally sent to the brain area for perception and recognition [12].

Inspired by the sensory nervous system, we tried to prove that the sensory synapses of the artificial neuron structure have the same perceptual behavior as biological perception. The schematic diagram of olfactory artificial neuron is revealed in Fig. 2b. It includes an ultra-thin PI substrate deposited with interdigital electrodes and a sensitive detection unit based on $\mathrm{CuS}$ QDs/ $/ \mathrm{Bi}_{2} \mathrm{~S}_{3} \mathrm{NSs}$ heterostructure. In the gas sensor, 0D-2D CuS QDs/ $/ \mathrm{Bi}_{2} \mathrm{~S}_{3}$ NSs are stacked on an ultra-thin PI substrate deposited with Au electrodes by inkjet printing (optical image in Fig. 2b-i). Besides, $\mathrm{NO}_{2}$ molecules with strong electron deprivation properties are adsorbed on the surface of artificial neurons in the sensing process, which triggers changes in the surface charge distribution by depriving them of charges and finally leads to the generation of electrical signals (Fig. 2b-ii).

\subsection{Artificial Neuron-like Sensing Layer Based on CuS $\mathrm{QDs} / \mathrm{Bi}_{2} \mathrm{~S}_{3}$ NSs Heterostructure}

To achieve ultra-sensitive detection, it is particularly important to construct a reasonable sensor layer of artificial olfactory neurons. As schematically shown in Fig. 3a, in brief, ultrasonic stripping of bulk $\mathrm{Bi}_{2} \mathrm{~S}_{3}$ was executed in a mixed solution of anhydrous ethanol and deionized water for the first time without any further complicated cleaning treatment. In stark contrast to commercial bulk $\mathrm{Bi}_{2} \mathrm{~S}_{3}$ (Fig. S2), 
(a)

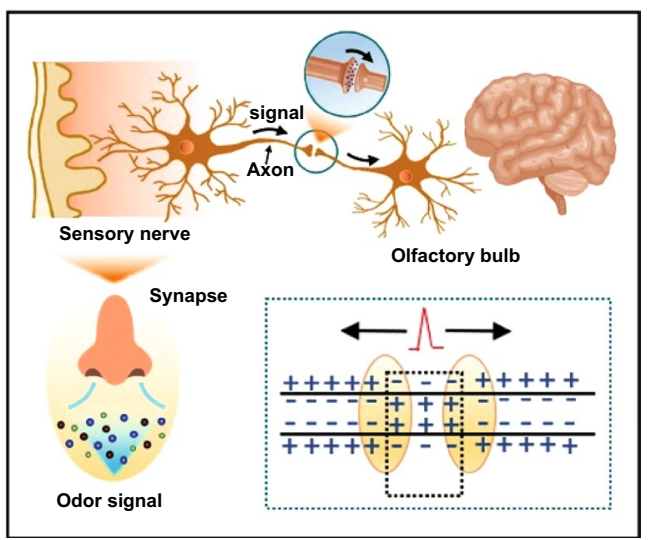

(d)

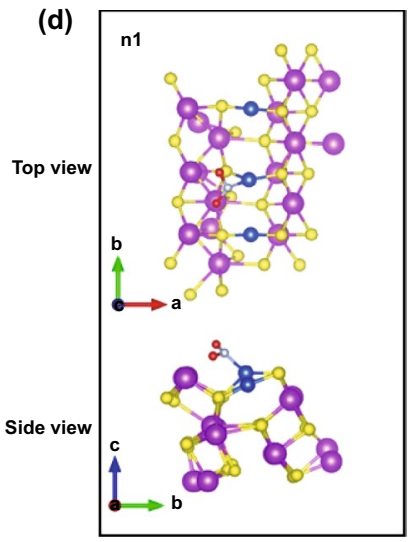

(e)

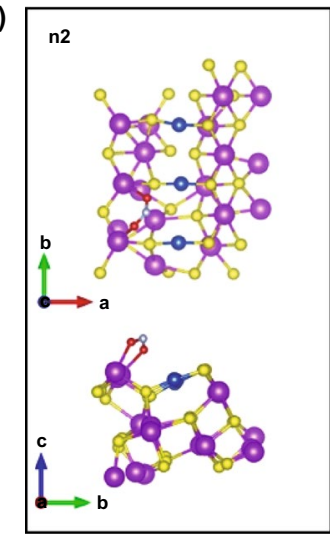

(b)

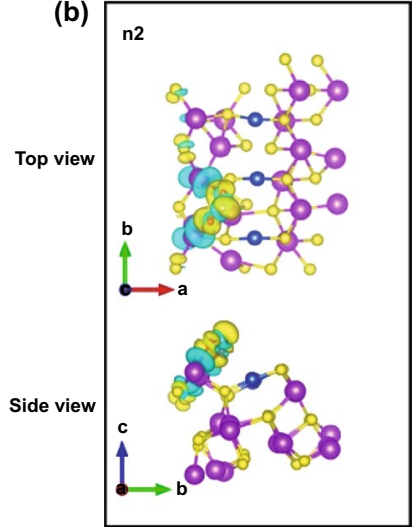

(f)

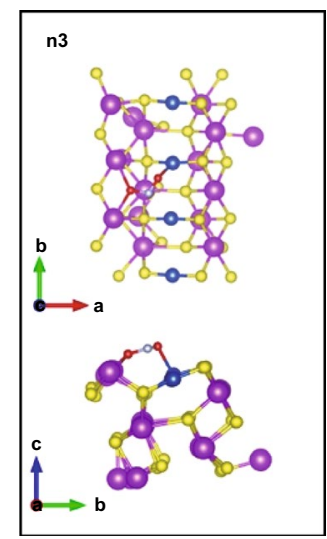

(c)

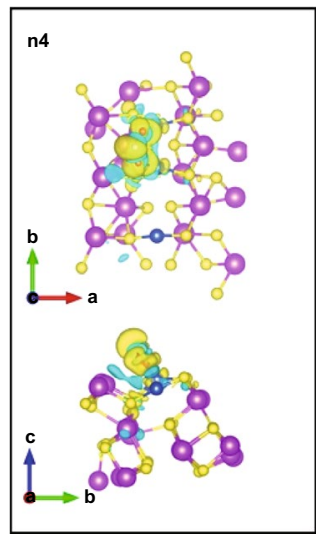

(g)

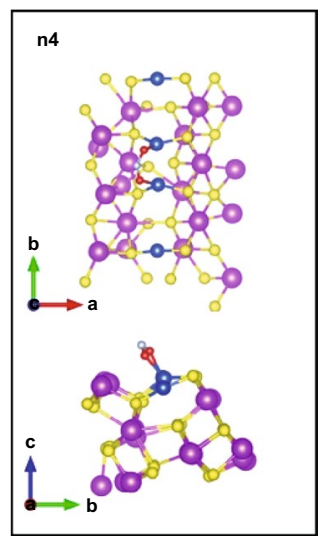

Fig. 1 a Schematic diagram of charge change of biological olfactory system during stimulation. Sensing mechanism and the possible interaction energy of gases with configurations on the $\mathrm{CuS}$ QDs $/ \mathrm{Bi}_{2} \mathrm{~S}_{3} \mathrm{NSs}$ using DFT calculations. $\mathbf{b}$ and $\mathbf{c}$ Diagrams of charge density difference of $\mathrm{NO}_{2}$ on $\mathrm{CuS}-\mathrm{Bi}_{2} \mathrm{~S}_{3}$ with $\mathrm{n} 2$ and $\mathrm{n} 4$ binding structure for side and top view, where the charge density isosurfaces of blue and yellow are 0.0015 and -0.0015 e A $\AA^{-3}$, respectively. d-g Binding structures of $\mathrm{NO}_{2}$ on $\mathrm{CuS}-\mathrm{Bi}_{2} \mathrm{~S}_{3}$

the lateral size and thickness of $\mathrm{Bi}_{2} \mathrm{~S}_{3}$ NSs were reduced from a few micrometers to the nanometer scale upon grinding and ultrasonic treatment.

Subsequently, a simple two-step chemical precipitation technique was designed to hybridize CuS QDs to the surface of $\mathrm{Bi}_{2} \mathrm{~S}_{3} \mathrm{NSs}$, and its chemical structure is shown in Fig. 3b. The composite structures of BC-5 (a series of $\mathrm{CuS}$ QDs modified $\mathrm{Bi}_{2} \mathrm{~S}_{3}$ NSs hybrid materials with different $\mathrm{CuS}$ content are numbered BC-n, where $\mathrm{n}$ is the mass percentage of CuS QDs in the hybrid material, $n=2.5,3,4,5,6,7.5$, 10 , and 20) were studied by SEM and TEM. As shown in Fig. 3c, the morphology of BC-5 keeps the same as the bare $\mathrm{Bi}_{2} \mathrm{~S}_{3} \mathrm{NSs}$, which still exhibits a nanosheet appearance as the lateral size of ca. $200 \mathrm{~nm}$ without an observable change in morphology upon the loading of CuS. The thin 2D structure supplies a boosted surface area for the CuS QDs loading.

CuS QDs $(\approx 8 \mathrm{~nm})$ uniformly distributed on the surface of $\mathrm{Bi}_{2} \mathrm{~S}_{3}$ NSs are observed in the TEM image (Fig. 3d).
Attribute to the higher surface energy at the edge positions of nanosheets and the individual distribution of quantum dots without agglomerates or clusters, the CuS QDs are prone to be attached to the edge positions of $\mathrm{Bi}_{2} \mathrm{~S}_{3} \mathrm{NSs}$. The intimate attachment of $\mathrm{CuS}$ QDs on $\mathrm{Bi}_{2} \mathrm{~S}_{3}$ NSs demonstrates the strong bonding and interacting heterogeneous structures at the interface, which is essential for their enhanced sensing performance [22, 26].

Based on the high-resolution TEM (HR-TEM), a $0.56 \mathrm{~nm}$ lattice spacing is found for $\mathrm{Bi}_{2} \mathrm{~S}_{3} \mathrm{NSs}$ and BC-5 (Figs. S2d and $3 \mathrm{e}$ ), which corresponds to the (020) facets of $\mathrm{Bi}_{2} \mathrm{~S}_{3}$ crystal and again supports the process of selective orientation stripping of $\mathrm{Bi}_{2} \mathrm{~S}_{3} \mathrm{NSs}$ [13]. Additionally, a lattice fringe spacing of $0.304 \mathrm{~nm}$ is also found in Fig. 3e, which can be ascribed to the crystallographic facet (102) of CuS. The confirmation of these lattices further proves that the construction of $\mathrm{CuS}$ QDs and $\mathrm{Bi}_{2} \mathrm{~S}_{3} \mathrm{NSs}$ forms a heterostructure rather than a simple physical mixing [27]. In addition, the 


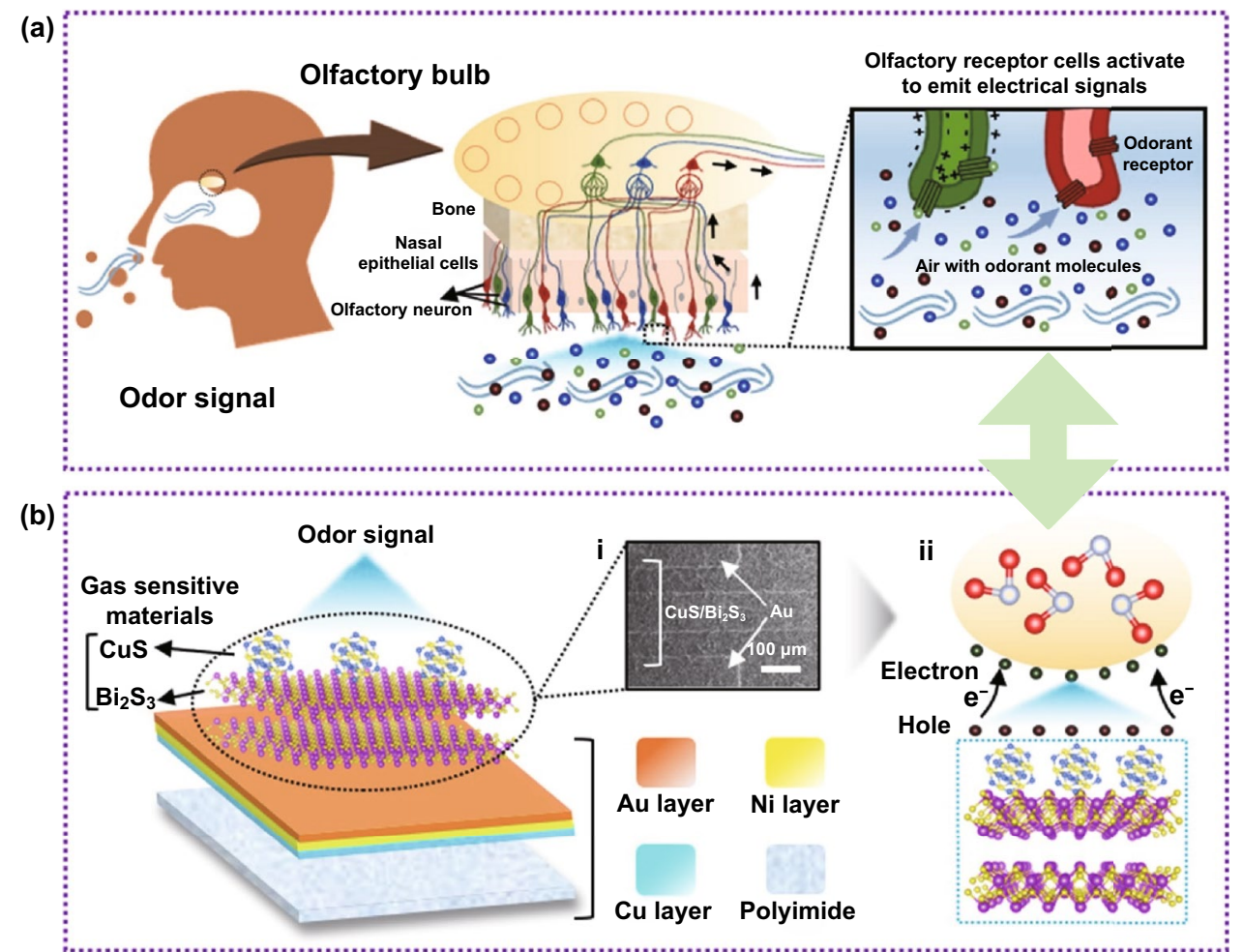

Fig. 2 a Schematic diagram of biological olfactory system. b Schematic diagram of artificial olfactory neuron sensing based on $\mathrm{CuS}$ QDs/Bi $\mathrm{S}_{3}$ NSs heterostructure

presence of $\mathrm{Bi}_{2} \mathrm{~S}_{3}$ NSs results in a more uniform loading of $\mathrm{CuS}$ QDs on its surface. The detailed microstructure of the irregular $\mathrm{CuS}$ without substrate nanosheets is indicated in Fig. S4c. The XRD confirmed the structural regularity of bulk material and the crystal planes of orthorhombic $\mathrm{Bi}_{2} \mathrm{~S}_{3}$. Exfoliated $\mathrm{Bi}_{2} \mathrm{~S}_{3} \mathrm{NSs}$ show preferential orientation along the (010) facet, which increases the intensity of the peaks including (130), (310) and (020) (Fig. S3a). In addition, a decrease in the overall peak intensity of the product sample has been observed, demonstrating that the exfoliation process distorts the crystal lattice [16, 28]. The similar Raman spectrum patterns of bulk material and thin layer are displayed in Fig. S3b, Supporting Information. The transverse in-plane $\mathrm{A}_{\mathrm{g}}$ vibration peaks occurring at 188 and $240 \mathrm{~cm}^{-1}$ and the longitudinal $\mathrm{B}_{1 \mathrm{~g}}$ vibrations at 168 and $265 \mathrm{~cm}^{-1}$ coincide with the values reported previously [29]. It is noteworthy that $\mathrm{Bi}_{2} \mathrm{~S}_{3}$ NSs have a similar Raman signal as bulk material, further confirming that the properties of nanosheets remain unchanged after liquid-phase exfoliation process.

XRD pattern of the $\mathrm{CuS}$ QDs/ $/ \mathrm{Bi}_{2} \mathrm{~S}_{3}$ NSs (Fig. 2f) is specifically indexed into orthorhombic $\mathrm{Bi}_{2} \mathrm{~S}_{3}$ and hexagonal
$\mathrm{CuS}[27,30]$. As a blank control, bare $\mathrm{CuS}$ was prepared without the loading of $\mathrm{Bi}_{2} \mathrm{~S}_{3} \mathrm{NSs}$. The bare $\mathrm{CuS}$ has revealed a single-phase structure in XRD and Raman tests as expected in the pure hexagonal phase (Fig. S4) [31]. X-ray photoelectron spectroscopy (XPS) measurements have been further used to study the elements in $\mathrm{CuS} \mathrm{QDs} / \mathrm{Bi}_{2} \mathrm{~S}_{3} \mathrm{NSs}$ and other products. As displayed in Figs. 3g and S5, the full XPS spectrum of the heterostructure includes the corresponding peaks that are associated with $\mathrm{Bi}_{2} \mathrm{~S}_{3}$, while the peak at 931.9 and $951.7 \mathrm{eV}$, respectively, supports the presence of $\mathrm{Cu} 2 \mathrm{p}_{3 / 2}$ and $2 \mathrm{p}_{1 / 2}$ in $\mathrm{CuS}$ [32]. This confirms the successful formation of $\mathrm{CuS}$ and $\mathrm{Bi}_{2} \mathrm{~S}_{3}$ in the composite product, which shows no difference with XRD results.

To consider the potential distribution of the resting state of the artificial neuron sensor layer before being stimulated by the olfactory sense, the interface interaction between the CuS QDs and $\mathrm{Bi}_{2} \mathrm{~S}_{3} \mathrm{NSs}$ was further studied. The electronic structures of the composite products and the pure phase monomer constituent elements were studied by highresolution XPS measurement. As displayed in Fig. 4a, two separated peaks in the Bi $4 \mathrm{f}$ XPS spectrum at 158.3 and $163.6 \mathrm{eV}$ are $4 f_{7 / 2}$ and $4 f_{5 / 2}$ hybridized orbitals of the $\mathrm{Bi}$ 
(a)

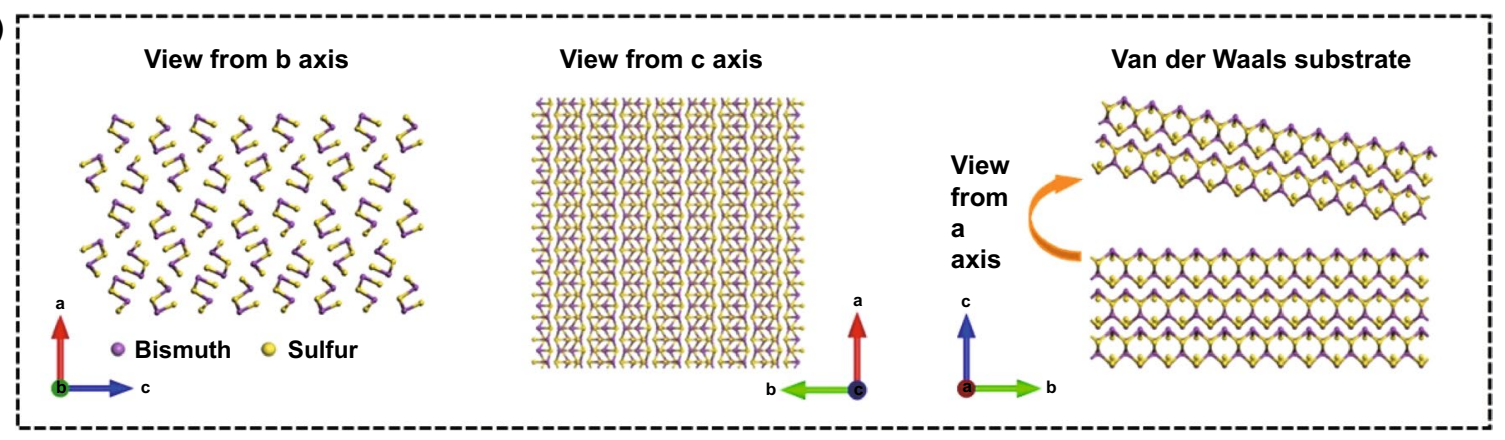

(b)

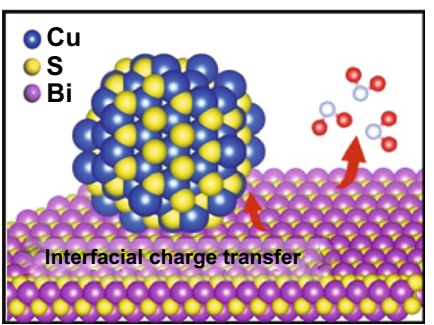

(e)

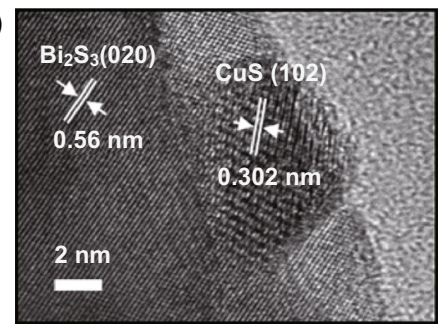

(c)

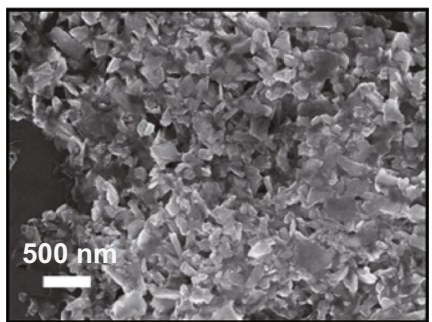

(f) CuS:PDF\#06-0464

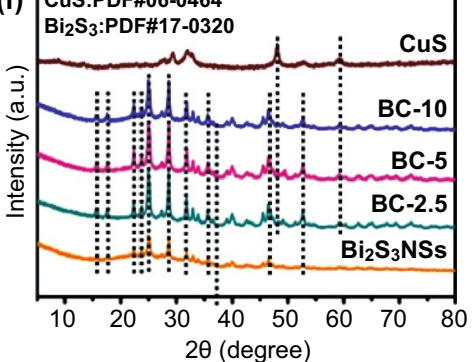

(d)

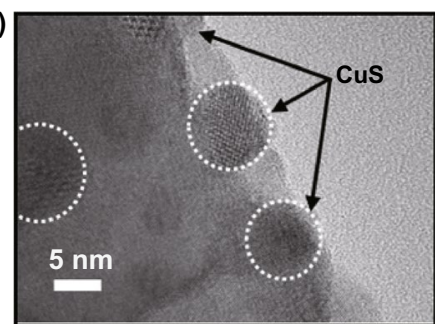

(g)

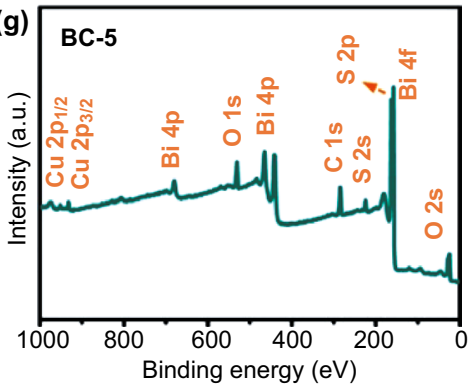

Fig. $3 \mathrm{CuS}$ QDs $/ \mathrm{Bi}_{2} \mathrm{~S}_{3} \mathrm{NSs}$ heterostructure and characterization of $\mathrm{CuS}$ and $\mathrm{Bi}_{2} \mathrm{~S}_{3} \mathrm{NSs}$. a Schematic diagram of crystal structure and fractureexfoliation process of $\mathrm{Bi}_{2} \mathrm{~S}_{3}$ bulk material with selective orientation. b Schematic representation of the atomic structure of CuS QDs/ Bi $\mathrm{S}_{3} \mathrm{NSs}$. c-e SEM, TEM and HR-TEM images of BC-5. f XRD patterns of CuS QDs/Bi $\mathrm{S}_{3}$ NSs, CuS and $\mathrm{Bi}_{2} \mathrm{~S}_{3}$ NSs. g Full XPS survey spectrum of BC-5

4f orbital energy level for BC-5 sample, respectively [33]. Compared with bare $\mathrm{Bi}_{2} \mathrm{~S}_{3} \mathrm{NSs}$, the peak position shifts to the high binding energy, indicating that the electron density on the $\mathrm{Bi}_{2} \mathrm{~S}_{3}$ surface in $\mathrm{BC}-5$ nanocomposites is reduced. Two peaks at 932.1 and $952.2 \mathrm{eV}$ of $\mathrm{Cu} 2 \mathrm{p}$ (Fig. 4b) can be regarded as the $\mathrm{Cu}^{2+}[30]$. Compared to bare $\mathrm{CuS}$, the peak position shifts about $1 \mathrm{eV}$ toward the lower binding energy, indicating an elevated electron density on the $\mathrm{Cu}$ surface in the BC-5 nanocomposite. Meanwhile, the S 2p XPS spectra in Fig. 4a, c show similar results. The results of these peak shifts prove the formation of heterogeneous structures. The charge transfer between the interfaces is from $\mathrm{Bi}_{2} \mathrm{~S}_{3}$ to $\mathrm{CuS}$. Moreover, the chemical bonds formed between $\mathrm{CuS}$ QDs and $\mathrm{Bi}_{2} \mathrm{~S}_{3} \mathrm{NSs}$ lead to the rapid migration of interfacial charges and induce the appearance of strong polarization and strong electric fields, which help to enhance the adsorption and desorption efficiency of $\mathrm{NO}_{2}[21,26,34]$.

To understand the charging behavior of the CuS QDs/ $\mathrm{Bi}_{2} \mathrm{~S}_{3} \mathrm{NSs}$, the charge density difference at the interface was studied using DFT calculation. As exhibited in Fig. S6 in Supporting Information, three $\mathrm{Cu}$ atoms in the CuS QDs/ $\mathrm{Bi}_{2} \mathrm{~S}_{3}$ NSs composite structure are bonded at the (010) crystal plane $\mathrm{S}-\mathrm{S}$ bridge site. From the three-dimensional migration diagram of the $\mathrm{CuS}$ QDs/ $\mathrm{Bi}_{2} \mathrm{~S}_{3}$ NSs interfacial charge in Fig. 4d, the CuS QDs/ $/ \mathrm{Bi}_{2} \mathrm{~S}_{3} \mathrm{NSs}$ interfacial charge shows a strong polarization, efficient electron-hole separation, and redistribution state. The differential charge density and bader charge transfer values are displayed in Table S3, showing a strong bonding formed between $\mathrm{CuS}$ and $\mathrm{Bi}_{2} \mathrm{~S}_{3}$, and the bader charge transfer value is $3.371 \mathrm{e}$, which illustrates the 
correctness of this structural model and proves that the interfacial charge is transferred from $\mathrm{Bi}_{2} \mathrm{~S}_{3}$ to $\mathrm{CuS}$.

Besides, to gain a deeper understanding of the redistribution of interfacial charges and to reveal the transition process of $\mathrm{Bi}_{2} \mathrm{~S}_{3} \mathrm{NSs}$ upon $\mathrm{CuS}$ QDs loaded on the surface, the energy band structure of the interface materials was further characterized. Herein, ultraviolet photoelectron spectroscopy (UPS) measurements are employed to establish the specific energy band location of heterojunction, where the position of the conduction band (CB), the Fermi energy level $\left(\mathrm{E}_{\mathrm{f}}\right)$, and the valence band maximum (VB) are determined by $\mathrm{E}_{\mathrm{f}}=21.22 \mathrm{eV}-\mathrm{E}_{\text {cutoff }}\left(\mathrm{E}_{\text {cutoff }}\right.$ is the energy at which the secondary light emission starts), $\mathrm{E}_{\mathrm{V}}=21.22 \mathrm{eV}-\left[\mathrm{E}_{\text {cutoff }}-\left(\mathrm{E}_{\mathrm{f}}-\mathrm{E}_{\mathrm{VM}}\right)\right]\left(\mathrm{E}_{\mathrm{VM}}\right.$ is the valence band maximum). Then, the bandgap values of $\mathrm{Bi}_{2} \mathrm{~S}_{3}$ and $\mathrm{CuS}$ were, respectively, determined to be 1.3 and $1.8 \mathrm{eV}$ from the UV-Vis diffuse reflectance spectra and the corresponding Tauc plots (Fig. S8) [35]. In addition, the Mott-Schottky technique is employed to study the semiconductor properties of interfacial materials, as well as flat-band potentials. As shown in Fig. 4g, h, the positive and negative slope indicates the n-type and p-type behavior of $\mathrm{Bi}_{2} \mathrm{~S}_{3}$ and $\mathrm{CuS}$, while its flat-band potential is calculated as $-0.34 \mathrm{~V}$, as well as $0.5 \mathrm{~V}$, respectively $[34,36]$.

Moreover, the specific energy band locations of heterojunction materials are described in Fig. S9 with a corresponding model to explain the interfacial charge redistribution. When the two different semiconductors at the interface come into contact, due to the distance between the $\mathrm{E}_{\mathrm{f}}$ of $\mathrm{Bi}_{2} \mathrm{~S}_{3}$ and the vacuum electron energy level $\left(\mathrm{E}_{\mathrm{vac}}\right)$ of
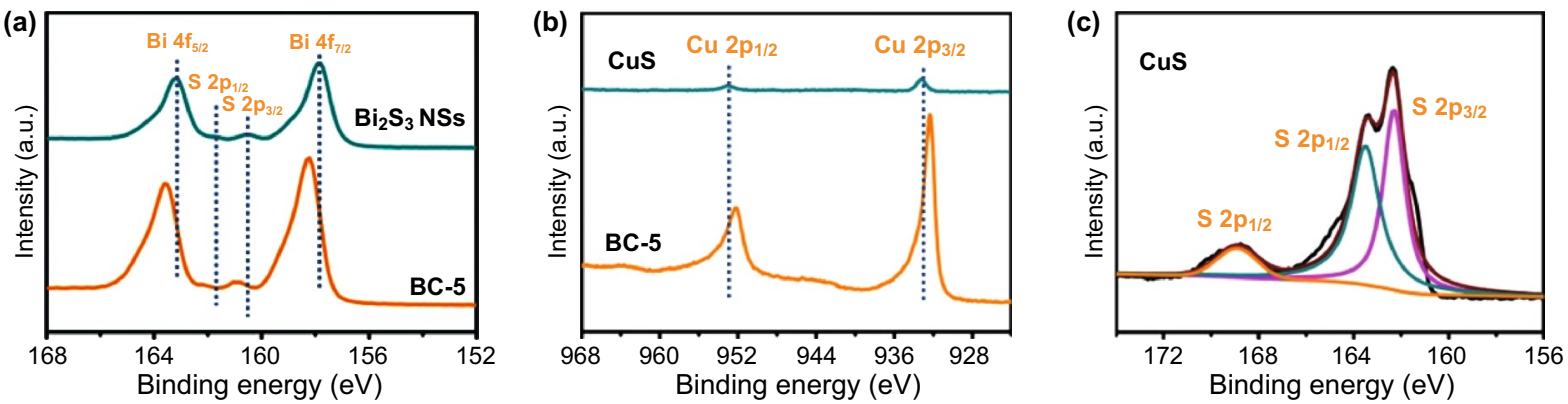

(d)
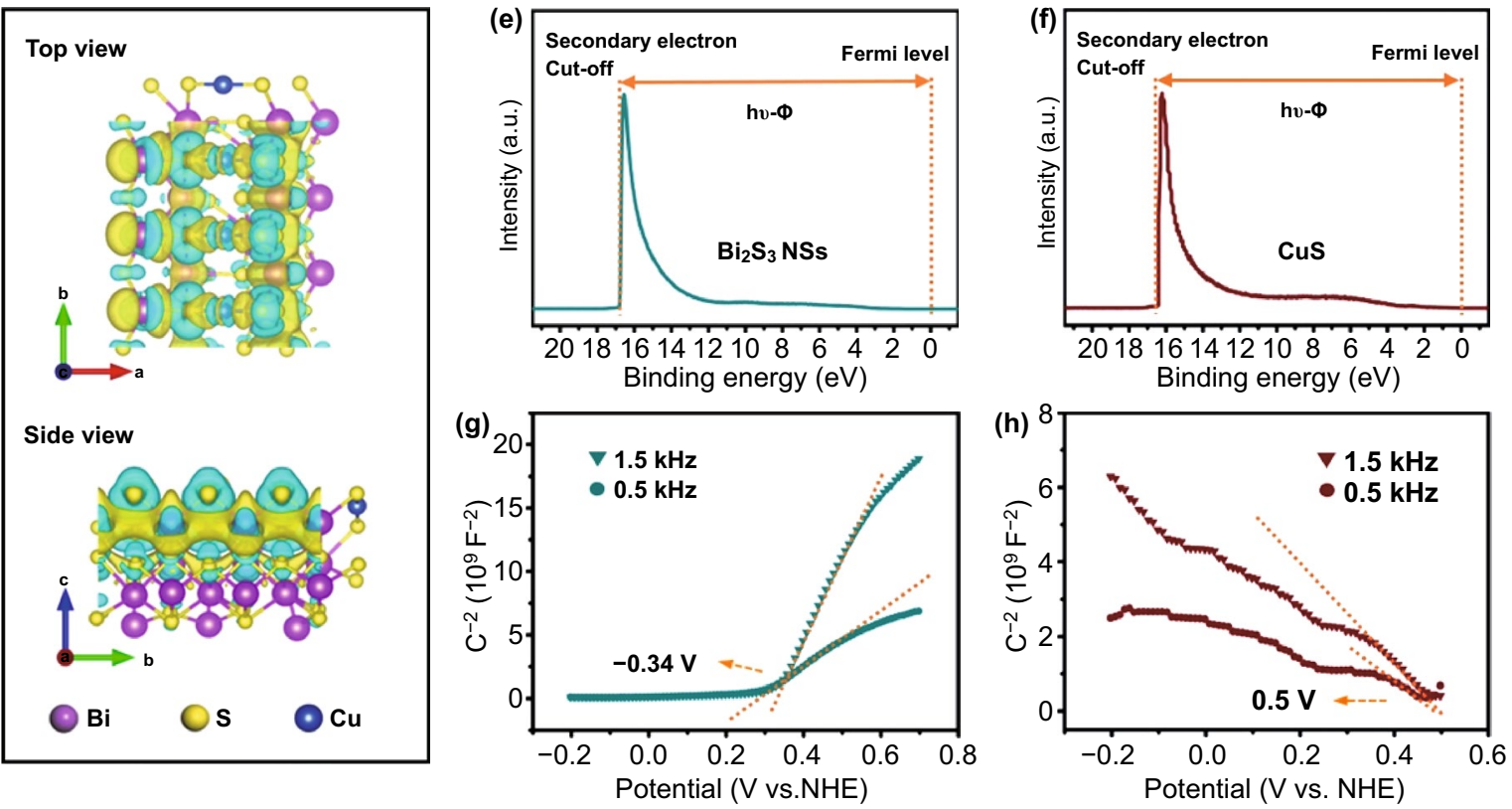

Fig. 4 Analysis of interface charge state of the heterostructure. a-c High-resolution XPS spectra of Bi 4f, Cu 2p and S 2p of the BC-5, CuS, and $\mathrm{Bi}_{2} \mathrm{~S}_{3}$ NSs. d Charge distribution at the interface of CuS QDs and $\mathrm{Bi}_{2} \mathrm{~S}_{3}$ NSs calculated by density functional theory. UPS spectra of $\mathbf{e} \mathrm{Bi}_{2} \mathrm{~S}_{3}$ and f CuS. Mott - Schottky plots for $\mathbf{g} \mathrm{Bi}_{2} \mathrm{~S}_{3} \mathrm{NSs}$ and $\mathbf{h} \mathrm{CuS}$ 
$-4.37 \mathrm{eV}$, driven by the thermodynamic difference between the work function of $\mathrm{Bi}_{2} \mathrm{~S}_{3}(-4.37 \mathrm{eV})$ and $\mathrm{CuS}(-4.79 \mathrm{eV})$, electrons will spontaneously transfer from $\mathrm{Bi}_{2} \mathrm{~S}_{3}$ to $\mathrm{CuS}$ across the interface, thus forming an electron depletion layer on the surface of $\mathrm{Bi}_{2} \mathrm{~S}_{3}$. On the contrary, holes of p-type $\mathrm{CuS}$ near the interface tend to diffuse into n-type $\mathrm{Bi}_{2} \mathrm{~S}_{3}$, thus establishing a hole depletion layer on the $\mathrm{CuS}$ surface. The electron-hole diffusion continues until the heterojunction establishes a uniform $\mathrm{E}_{\mathrm{f}}$, which conduces to the energy band bending at the interface. Furthermore, the $\mathrm{CuS} \mathrm{QDs} / \mathrm{Bi}_{2} \mathrm{~S}_{3}$ NSs $p-n$ junction exhibits a type-II band structure, which is conducive to inhibit electron-hole recombination [37].

\subsection{Sensing Performance of the Artificial Olfactory Neuron-like Sensor}

To assess the effect of interfacial electrons on materials after the construction of heterogeneous structures, the sensing material was sprayed on the electrode surface using inkjet printing technology, and the change of its gas-sensitive performance was studied in a homemade dynamic sensing system (Figs. S10 and S11). The variation in sensing performance of starting bulk materials, $\mathrm{Bi}_{2} \mathrm{~S}_{3} \mathrm{NSs}$, and CuS QDs/ $\mathrm{Bi}_{2} \mathrm{~S}_{3} \mathrm{NSs}$ with different weight ratios for $10 \mathrm{ppm} \mathrm{NO} \mathrm{NO}_{2}$ is displayed in Figs. 5a, S12 and S13. The exfoliated $\mathrm{Bi}_{2} \mathrm{~S}_{3} \mathrm{NSs}$ showed greater electrical resistance compared to the bulk material, which was ascribed to the large number of defects introduced after liquid-phase exfoliation (Table S4) [17, 26]. The pristine $\mathrm{Bi}_{2} \mathrm{~S}_{3}$ displayed an increase in resistance immediately after being exposed to $\mathrm{NO}_{2}$, indicating an n-type semiconducting property as identical to the Mott-Schottky (M-S) test results. Meanwhile, the larger specific surface area after exfoliation enriches the number of the active sites on the samples, resulting in increased response and reduced recovery performance.

When CuS QDs are loaded at the lower concentrations (2.5 wt \% and $3 \mathrm{wt} \%$ ), an increase in the sample resistance, as well as a decrease in the response magnification, can be observed, which can be attributed to the recombination of electrons in $\mathrm{Bi}_{2} \mathrm{~S}_{3} \mathrm{NSs}$ with holes from the p-type CuS. As the loading amount of CuS QDs further increases (beyond $4 \mathrm{wt} \%$ ), the sensor exhibits a decreasing resistance change in the presence of $\mathrm{NO}_{2}$, indicating that the n-type $\mathrm{Bi}_{2} \mathrm{~S}_{3}$ has been completely transformed into a p-type complex by the multiple (hole) injection of p-type CuS. This result suggests that the $\mathrm{CuS}$ QDs/ $/ \mathrm{Bi}_{2} \mathrm{~S}_{3} \mathrm{NSs}$ possess a complete transition of n- to p-type in semiconductor properties. When the $\mathrm{CuS}$ QDs loading on the surface of $\mathrm{Bi}_{2} \mathrm{~S}_{3} \mathrm{NSs}$ is further increased (over $6 \mathrm{wt} \%$, until it reaches bare $\mathrm{CuS}$ ), a further decrease in the surface resistance of sensitive materials is observed. This phenomenon is attributed to the further increase in the majority carrier (hole) concentration of the p-type semiconductor composite product. The continuous improvement of the conductivity of sensitive materials makes the resistance change more difficult to be observed, which is manifested as a decrease in the response rate [38].

By comparing the response and recovery properties of the heterojunction-based sensors with different CuS QDs loadings to $10 \mathrm{ppm} \mathrm{NO}, \mathrm{BC}-5$ has been identified as the optimal device with a response amplification of 3.4 and ultra-fast response and recovery rates (18 and $338 \mathrm{~s}$, respectively) without the assistance of any additional means. Our BC-5 has shown a grand advance in sensing performance over the previously reported works on $\mathrm{NO}_{2}$ room temperature flexible sensors (Table S5). According to the previous DFT calculations, compared to the initial bulk $\mathrm{Bi}_{2} \mathrm{~S}_{3}$ material, the reason for the superior performance of the BC-5-based sensor attributes to the construction of many sensitive points and the rapid conduction of charges.

To reveal the importance of reversibility for $\mathrm{BC}-5$-based gas sensors, the cyclic test is executed to $10 \mathrm{ppm} \mathrm{NO}_{2}$. The sensing performance was kept nearly unchanged after five cycle uses (Fig. 5b). In addition, Fig. 5c shows the responserecovery curves of the $\mathrm{BC}-5$-based sensor exposed to $\mathrm{NO}_{2}$ at concentrations of $500 \mathrm{ppb}$ to $100 \mathrm{ppm}$. With the response change and error bar data summarized in Fig. S13, BC5-based sensors exhibit excellent sensitivity and recovery capability. The theoretical limit of detection (LOD) of the device toward $\mathrm{NO}_{2}$ was calculated as approximately $78 \mathrm{ppb}$ by the least squares method using $3 \mathrm{RMS}_{\text {noise }}$ divided by the slope of the low-concentration partial fit curve (Fig. S14b) $[8,39]$. The fitted curve shows a dichotomous distribution due to the scattering effect of $\mathrm{NO}_{2}$ molecules resulting in reduced carrier mobility [40].

To study the sensing performance of the device in the real environment, we have further investigated its longterm stability and selectivity. The long-term stability of BC-5-based sensor was estimated upon exposure to $10 \mathrm{ppm}$ $\mathrm{NO}_{2}$ for 2 months at an interval of 1 week (Fig. S14c). The response value of the device remained virtually unchanged for two months, indicating excellent long-term stability. 

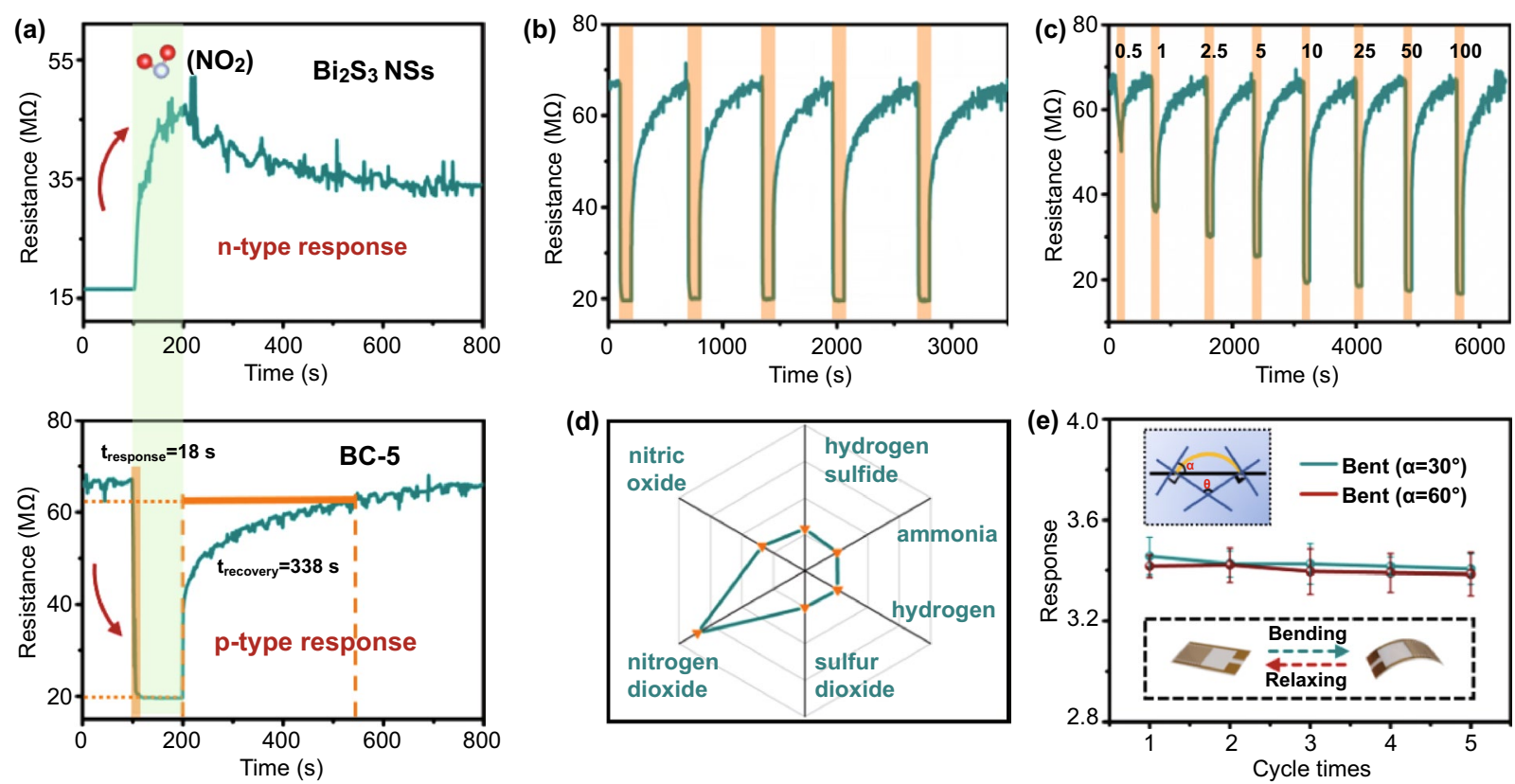

Fig. $5 \mathrm{NO}_{2}$ sensing performances $\mathrm{BC}-5$-based sensor. a Resistance variation for the device to $\mathrm{NO}_{2}$ at 10 ppm concentration. b Response-recovery curve of the device for 5 cycles to $10 \mathrm{ppm} \mathrm{NO}_{2}$. c Transient response-recovery curve for the device to $\mathrm{NO}_{2}$ with different concentrations. d

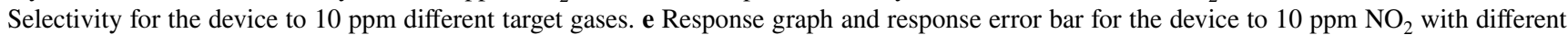
bending angles

This result indicates that the depletion layer formed at the interface by our heterostructure building process can act as a passivation layer, preventing environmental oxidation of sulfides and leading to reliable long-term stability [41, 42]. Furthermore, the selectivity of BC-5-based sensor for different gases was tested. Different analytes were investigated including $10 \mathrm{ppm} \mathrm{NO} \mathrm{NO}_{2} \mathrm{~S}, \mathrm{NH}_{3}, \mathrm{SO}_{2}, \mathrm{H}_{2}$, and NO. As shown in Figs. $5 \mathrm{~d}$ and $\mathrm{S} 15$, the response value for $\mathrm{NO}_{2}$ was significantly higher than other test gases, indicating that the device exhibited excellent selectivity. Besides, considering the influence of humidity, the sensor was exposed to $10 \mathrm{ppm}$ $\mathrm{NO}_{2}$ with relative humidity ranging from 0 to $80 \%$ (Fig. $\mathrm{S} 16$ ). The response value decreases from 3.4 to 1.6 as the relative humidity increased, indicating that the sensor can still work normally under high humidity conditions. The negligible decrease in response is probably arising from the fact that some $\mathrm{H}_{2} \mathrm{O}$ molecules occupy the sensing sites [43].

In addition, the illustration of Fig. 5e depicts a schematic diagram of the mechanical strain bending direction of the flexible device. The flexible sensor was bent at $30^{\circ}$ and $60^{\circ}$ followed by sensing tests in $10 \mathrm{ppm} \mathrm{NO}_{2}$ for five cycles. The response results of the device clearly showed that the bending of the flexible electrode will not reduce the property of the as-prepared device.

\subsection{Gas sensing Mechanisms of the Artificial Neuron-like Olfactory System}

Based on the DFT calculations and the corresponding experimental results, we conducted an in-depth understanding and discussion on the mechanism of the artificial neuron-like sensor based on $\mathrm{CuS}$ QDs $/ \mathrm{Bi}_{2} \mathrm{~S}_{3} \mathrm{NSs}$ to enhance the $\mathrm{NO}_{2}$ sensing performance.

First of all, the DFT calculation results prove that in the neuron-like sensor model constructed by the olfactory sensory neurons, a large number of dispersed OD CuS QDs can be used as $\mathrm{NO}_{2}$ sensitive points to efficiently capture gas molecules. The $2 \mathrm{D} \mathrm{Bi}_{2} \mathrm{~S}_{3} \mathrm{NSs}$ as a conductive network and a heterojunction substrate can achieve rapid charge transfer through synergy.

Secondly, the artificial olfactory neuron sensor based on the heterogeneous structure of $\mathrm{CuS}$ QDs/ $/ \mathrm{Bi}_{2} \mathrm{~S}_{3} \mathrm{NSs}$ has the same charge transfer method as the biological olfactory perception process in the resting state and after being stimulated 
by gas molecules. The charge distribution process of the $\mathrm{CuS}$ QDS/ $/ \mathrm{Bi}_{2} \mathrm{~S}_{3} \mathrm{NSs}$ heterostructure itself in the resting state was studied in the previous chapter. In brief, upon intimate contact, electrons move spontaneously from $\mathrm{Bi}_{2} \mathrm{~S}_{3}$ to $\mathrm{CuS}$ across the interface for the equilibrium of Fermi level, leading to the formation of the electron and hole depletion layer on the surface of $\mathrm{Bi}_{2} \mathrm{~S}_{3}$ and $\mathrm{CuS}$, respectively. In addition, the formation of a built-in electric field and the bending of energy band also occur.

As shown in Fig. S17, when exposed to $\mathrm{NO}_{2}$ (electron acceptor), gas molecules are adsorbed onto the CuS QDs surface and trap electrons, breaking the equilibrium of the built-in electric field formed previously. The additional holes return to $\mathrm{CuS}$ that change the width of the potential barrier until formed a new equilibrium. The presence of a potential barrier in the heterojunction at the interface can reflect small fluctuations in carrier concentration due to the adsorption of $\mathrm{NO}_{2}$ molecules as large changes in resistance, which undoubtedly facilitates the response process [44]. In addition, the built-in electric field can also accelerate the charge carrier transfer efficiency, so as to improve the sensing performance $[45,46]$.

Furthermore, the switch from n-type to p-type character and the construction of surface heterostructures also affects the selectivity of the device. Compared with other gases, the adsorption of $\mathrm{NO}_{2}$ with a higher charge density can significantly increase the heterojunction barrier and improve its sensing performance [37]. The design of this series of interfacial heterostructures and charge modulation successfully enhanced the room temperature sensing performance of the artificial olfactory neuron-like sensors for $\mathrm{NO}_{2}$, making it significantly better than the previously reported $\mathrm{Bi}_{2} \mathrm{~S}_{3}$-based sensors and providing a new idea for the design of the heterogeneous interface of the biological simulation artificial olfactory neuron sensor.

\subsection{Wireless Wearable Devices and Real-time Monitoring of $\mathrm{NO}_{2}$}

In the previous content, we correlated the process of biological olfactory perception with the electrical signal generation and transmission process of the artificial neuron-like sensor in the process of detecting gas. The result of the transmission of sensory signals in the organism is the reception, analysis and response of the central nervous system of the brain. This series of processes is consistent with the sensor's back-end information collection and real-time data extraction. Previously, many flexible gas sensors have been developed while their real-world applications in wireless and wearable electronics still confront a challenge and are rarely demonstrated [47]. Intending to design wearable applications in real time, we integrated $\mathrm{CuS}$ QDs $/ \mathrm{Bi}_{2} \mathrm{~S}_{3}$ NSs-based artificial neuronlike sensor, circuit, and data acquisition to develop a portable $\mathrm{NO}_{2}$-monitoring system (Fig. 6a).

The hardware and software block diagram of the asprepared device system is illustrated in Fig. 6b. During the operation of the device, Bluetooth communication is first turned on, and the mobile device equipped with the selfdeveloped Android-based application scans the surrounding Bluetooth devices and verifies and connects after finding a matching sensing device. After the connection, the application will request the data acquisition circuitry for information such as the sensor's output voltage and real-time time. Once the data are obtained, the application can calibrate the ambient temperature and humidity, connect to a database to calculate the corresponding environmental pollution conditions, and display the relevant gas concentrations in real-time according to the requirements written. Moreover, by presetting the threshold value, the user can be warned in time when the pollution is aggravated and the gas concentration exceeds the standard.

For the working tests in this paper, a $200 \mathrm{mAh}$ rechargeable lithium-polymer battery (TF402030) was used to provide the appropriate voltage for all circuits, and the actual voltage on the flexible sensing device was $3.3 \mathrm{~V}$ (device circuit schematic is displayed in Fig. S18). The double-sided copper-clad flexible PCB is connected to the PI flexible electrode deposited with the gold finger by flexible silver wires (Fig. S19a), ensuring the flexibility of the wearable device and the accuracy of data transmission. The entire wireless wearable sensing device was tested for $\mathrm{NO}_{2}$ atmosphere in a fume hood at room temperature. In the actual test procedure, the signal connection and transmission from the Bluetooth device were first performed (Fig. S19b and Video S1), followed by a drop in the resistance value on the mobile application with the tube placed beside the device, i.e., the $\mathrm{NO}_{2}$ signal was detected. As the gas tube is removed, the curve trajectory spontaneously 
returns to the baseline (Fig. 6c). Also, given the fact that the interface-modulated $\mathrm{CuS} \mathrm{QDs} / \mathrm{Bi}_{2} \mathrm{~S}_{3} \mathrm{NSs}$ were able to return the signal to baseline without external assistance, we tested a continuous response for $4 \mathrm{~min}$ and revealed it on a phone application to demonstrate the reproducibility (Fig. S19c and Video S2).
The results presented herein efficiently cross-fertilize the fields of biological neuron-like sensing unit design, mechanical circuit fabrication, and software development to successfully develop wearable sensing devices that are lightweight, visual, and multifunctional. The advantages of biomimetic association, cheap, and low power

(a)

(b)
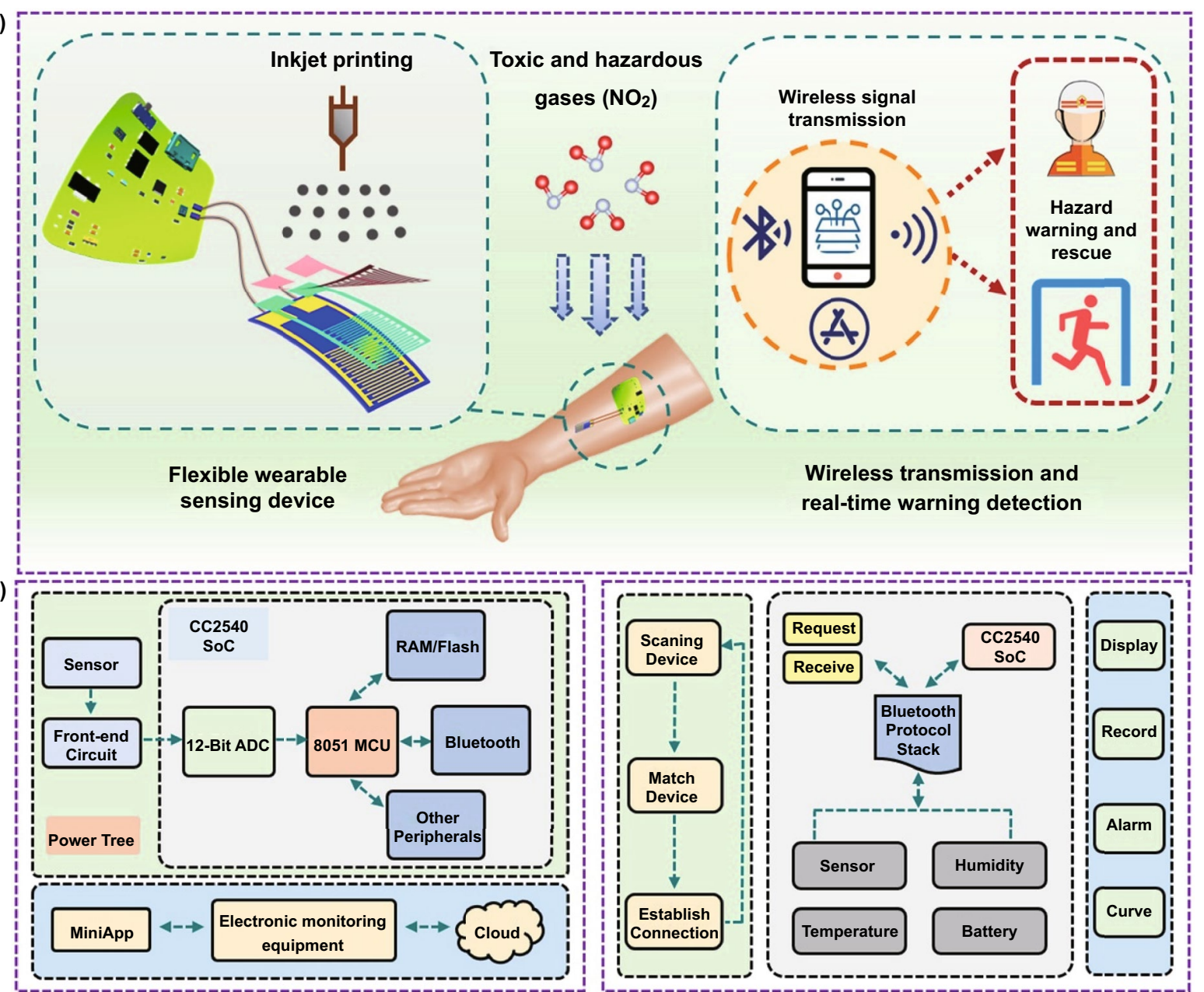

(c)

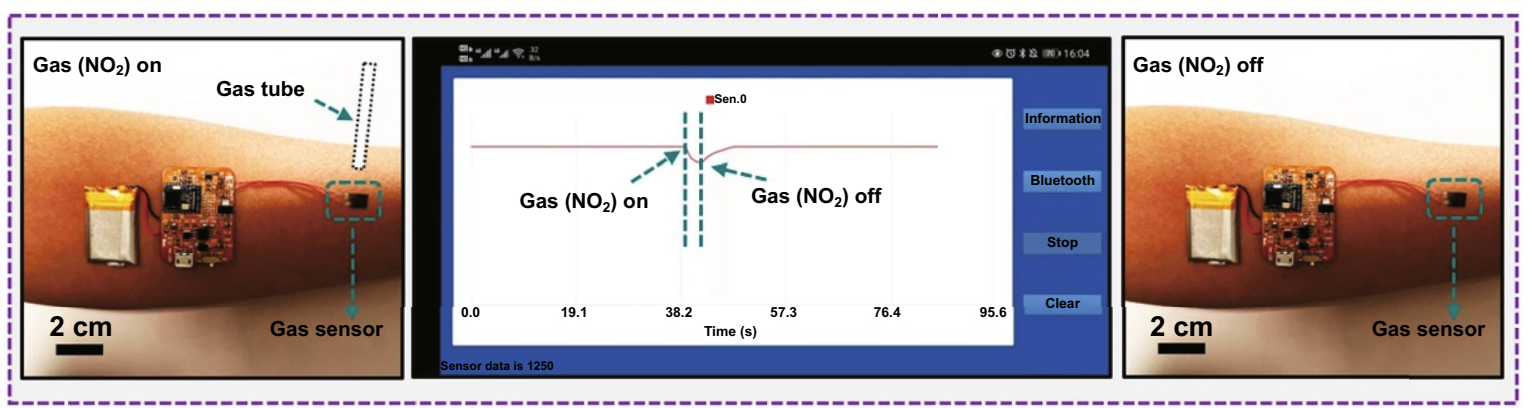

Fig. 6 Application process of the wireless wearable sensor system. a Schematic diagram of structure and application concept of wireless wearable devices. b Circuit hardware and software logic block diagram. c Photographs of the change in response to $\mathrm{NO}_{2}$ gas by smartphone application during the actual test 
consumption allow for sustainable utilization, and the development of wireless data transmission coincides with the expansion of the modern Internet of Things.

\section{Conclusions}

In summary, a self-designed bio-simulated neuron-like gas sensor that can drive wireless wearable devices for real-time monitoring of $\mathrm{NO}_{2}$ has been reported. First, $\mathrm{OD}$ p-type CuS QDs were successfully loaded onto the surface of $2 \mathrm{D}$ n-type $\mathrm{Bi}_{2} \mathrm{~S}_{3} \mathrm{NSs}$. Characterization analysis and DFT calculations were used for the first time to reveal that the charge transfer process of artificial neuron-like sensors in the resting state and when stimulated by gas is consistent with the process of biological olfactory perception. Moreover, the heterogeneous integration of artificial neuron-like sensor was unveiled that synergistically combines CuS QDs sites with high adsorption energy for target gas molecules and $\mathrm{Bi}_{2} \mathrm{~S}_{3} \mathrm{NSs}$ as fast charge transport channels. Compared with traditional bulk sensing materials, the problem of high-efficiency detection at room temperature can be effectively solved by this type of artificial neuronlike sensor through many scattered sensitive points. This exhibits an ultra-fast response (18 s) and recovery (338 s), an exceptional theoretical detection limit (78 ppb), a tunable sensing mechanism, and excellent selectivity. Second, through the low-concentration $\mathrm{NO}_{2}$ ventilation analysis of the wearable gas sensing device on the arm of the human subject, the visualization and real-time observation of the target gas on the smartphone app is realized. This artificial neuron-like device establishes a promising platform for the next generation of simulating complex biological nervous systems and promoting the development of artificial intelligence.

Acknowledgements This work was supported by the National Natural Science Foundation of China (61971284), the Oceanic Interdisciplinary Program of Shanghai Jiao Tong University (SL2020ZD203 and SL2020MS031) and Scientific Research Fund of Second Institute of Oceanography, Ministry of Natural Resources of P. R. China (SL2003), Shanghai Sailing Program (21YF1421400) and Startup Fund for Youngman Research at Shanghai Jiao Tong University. We also acknowledge analysis support from the Instrumental Analysis Center of Shanghai Jiao Tong University and the Center for Advanced Electronic Materials and Devices of Shanghai Jiao Tong University. The computations in this paper were run on the $\pi 2.0$ cluster supported by the Center for High Performance Computing at Shanghai Jiao Tong University.
Funding Open access funding provided by Shanghai Jiao Tong University.

Open Access This article is licensed under a Creative Commons Attribution 4.0 International License, which permits use, sharing, adaptation, distribution and reproduction in any medium or format, as long as you give appropriate credit to the original author(s) and the source, provide a link to the Creative Commons licence, and indicate if changes were made. The images or other third party material in this article are included in the article's Creative Commons licence, unless indicated otherwise in a credit line to the material. If material is not included in the article's Creative Commons licence and your intended use is not permitted by statutory regulation or exceeds the permitted use, you will need to obtain permission directly from the copyright holder. To view a copy of this licence, visit http://creativecommons.org/licenses/by/4.0/.

Supplementary Information The online version contains supplementary material available at https://doi.org/10.1007/ s40820-021-00740-1.

\section{References}

1. C. Figueres, P.J. Christiana, R. Fuller. Landrigan, Tackling air pollution, climate change, and NCDs: time to pull together. Lancet. 392(10157), 1502-1503 (2018). https://doi.org/10. 1016/S0140-6736(18)32740-5

2. X. Han, H.G.W. Godfrey, L. Briggs, A.J. Davies, Y. Cheng et al., Reversible adsorption of nitrogen dioxide within a robust porous metal-organic framework. Nat. Mater. 17, 691-696 (2018). https://doi.org/10.1038/s41563-018-0104-7

3. Z. Meng, R.M. Stolz, L. Mendecki, K.A. Mirica, Electricallytransduced chemical sensors based on two-dimensional nanomaterials. Chem. Rev. 119(1), 478-598 (2019). https://doi.org/ 10.1021/acs.chemrev.8b00311

4. A.V. Agrawal, N. Kumar, M. Kumar, Strategy and future prospects to develop room-temperature-recoverable $\mathrm{NO}_{2}$ gas sensor based on two-dimensional molybdenum disulfide. Nano-Micro Lett. 13, 38 (2021). https://doi.org/10.1007/ s40820-020-00558-3

5. Y. Pang, Z. Yang, Y. Yang, T.L. Ren, Wearable electronics based on 2D materials for human physiological information detection. Small 16, 1901124 (2019). https://doi.org/10.1002/ smll.201901124

6. M.A.A. Mamun, M.R. Yuce, Recent progress in nanomaterial enabled chemical sensors for wearable environmental monitoring applications. Adv. Funct. Mater. 30, 2005703 (2020). https://doi.org/10.1002/adfm.202005703

7. N. Tang, C. Zhou, L. Xu, Y. Jiang, H. Qu et al., A fully integrated wireless flexible ammonia sensor fabricated by soft nano-lithography. ACS Sens. 4(3), 726-732 (2019). https:// doi.org/10.1021/acssensors.8b01690

8. S. Guo, D. Yang, S. Zhang, Q. Dong, B. Li et al., Development of a cloud-based epidermal $\mathrm{MoSe}_{2}$ device for hazardous gas 
sensing. Adv. Funct. Mater. 29, 1900138 (2019). https://doi. org/10.1002/adfm.201900138

9. S.T. Keene, C. Lubrano, S. Kazemzadeh, A. Melianas, Y. Tuchman et al., A biohybrid synapse with neurotransmittermediated plasticity. Nat. Mater. 19, 969-973 (2020). https:// doi.org/10.1038/s41563-020-0703-y

10. J.R. Yu, X.X. Yang, G.Y. Gao, Y. Xiong, Y.F. Wang et al., Bioinspired mechano-photonic artificial synapse based on graphene/MoS 2 heterostructure. Sci. Adv. 7, eabd9117 (2021). https://advances.sciencemag.org/content/7/12/eabd9117

11. Q.B. Zhu, B. Li, D.D. Yang, C. Liu, S. Feng et al., A flexible ultrasensitive optoelectronic sensor array for neuromorphic vision systems. Nat. Commun. 12, 1798 (2021). https://doi. org/10.5281/zenodo.4540948

12. E. Chong, M. Moroni, C. Wilson, S. Shoham, S. Panzeri et al., Manipulating synthetic optogenetic odors reveals the coding logic of olfactory perception. Science 368, 1329 (2020). https://science.sciencemag.org/content/368/6497/eaba2357

13. X. Yang, S. Tian, R. Li, W. Wang, S. Zhou, Use of singlecrystalline $\mathrm{Bi}_{2} \mathrm{~S}_{3}$ nanowires as room temperature ethanol sensor synthesized by hydrothermal approach. Sens. Actuators B: Chem. 241, 210-216 (2017). https://doi.org/10.1016/j.snb. 2016.10.074

14. T.X. Fu, Gas sensor based on three dimensional $\mathrm{Bi}_{2} \mathrm{~S}_{3}$ nanowires network for ammonia detection at room temperature. Mater. Res. Bull. 99, 460-465 (2018). https://doi.org/ 10.1016/j.materresbull.2017.11.038

15. N. Dhar, N. Syed, M. Mohiuddin, A. Jannat, A. Zavabeti et al., Exfoliation behavior of van der waals strings: case study of $\mathrm{Bi}_{2} \mathrm{~S}_{3}$. ACS Appl. Mater. Interfaces 10(49), 4260342611 (2018). https://doi.org/10.1021/acsami.8b14702

16. W. Huang, C. Xing, Y. Wang, Z. Li, L. Wu et al., Facile fabrication and characterization of two-dimensional bismuth(III) sulfide nanosheets for high-performance photodetector applications under ambient conditions. Nanoscale 10, 2404-2412 (2018). https://doi.org/10.1039/C7NR0 $9046 \mathrm{C}$

17. Y.T. Han, D. Huang, Y.J. Ma, G.L. He, J. Hu et al., Design of hetero-nanostructures on $\mathrm{MoS}_{2}$ nanosheets to boost $\mathrm{NO}_{2}$ room-temperature sensing. ACS Appl. Mater. Interfaces 10, 22640-22649 (2018). https://doi.org/10.1021/acsami.8b05811

18. M. Ikram, L. Liu, Y. Liu, M. Ullah, L. Ma et al., Controllable synthesis of $\mathrm{MoS}_{2} @ \mathrm{MoO}_{2}$ nanonetworks for enhanced $\mathrm{NO}_{2}$ room temperature sensing in air. Nanoscale 11, 8554-8564 (2019). https://doi.org/10.1039/C9NR00137A

19. F.A. Sabah, N.M. Ahmed, Z. Hassan, H.S. Rasheed, High performance $\mathrm{CuS}$ p-type thin film as a hydrogen gas sensor. Sens. Actuators A: Phys. 249, 68-76 (2016). https://doi.org/ 10.1016/j.sna.2016.08.026

20. T. Ahamad, M. Naushad, S.M. Alshheri, Fabrication of highly porous N/S doped carbon embedded with $\mathrm{CuO} / \mathrm{CuS}$ nanoparticles for $\mathrm{NH}_{3}$ gas sensing. Mater. Lett. 268, 127515 (2020). https://doi.org/10.1016/j.matlet.2020.127515

21. H. Wang, K.Y. Xie, Y. You, Q. Hou, K. Zhang et al., Realizing interfacial electronic interaction within $\mathrm{ZnS}$ quantum dots/N-rGO heterostructures for efficient $\mathrm{Li}-\mathrm{CO}_{2}$ batteries.
Adv. Energy Mater. 9, 1901806 (2019). https://doi.org/10. 1002/aenm.201901806

22. X. Xin, Y. Zhang, X. Guan, J. Cao, W. Li et al., Enhanced performances of $\mathrm{PbS}$ quantum-dots-modified $\mathrm{MoS}_{2}$ composite for $\mathrm{NO}_{2}$ detection at room temperature ACS Appl. Mater. Interfaces 11(9), 9438-9447 (2019). https://doi.org/10.1021/ acsami.8b20984

23. E.P. Nguyen, B.J. Carey, T. Daeneke, J.Z. Ou, K. Latham et al., Investigation of two-solvent grinding-assisted liquid phase exfoliation of layered $\mathrm{MoS}_{2}$. Chem. Mater. 27(1), 53-59 (2015). https://doi.org/10.1021/cm502915f

24. Y. Yao, L. Tolentino, Z. Yang, X. Song, W. Zhang et al., High-concentration aqueous dispersions of $\mathrm{MoS}_{2}$. Adv. Funct. Mater. 23, 3577-3583 (2013). https://doi.org/10.1002/adfm. 201201843

25. X.W. Chen, S. Wang, C. Su, Y.T. Han, C. Zou et al., Twodimensional Cd-doped porous $\mathrm{Co}_{3} \mathrm{O}_{4}$ nanosheets for enhanced room-temperature $\mathrm{NO}_{2}$ sensing performance. Sens. Actuators B: Chem. 305, 127393 (2020). https://doi.org/10.1016/j.snb. 2019.127393

26. Y.T. Han, Y. Liu, C. Su, S.T. Wang, H. Li et al., Interface engineered $\mathrm{WS}_{2} / \mathrm{ZnS}$ heterostructures for sensitive and reversible $\mathrm{NO}_{2}$ room temperature sensing. Sens. Actuators B: Chem. 296, 126666 (2019). https://doi.org/10.1016/j.snb.2019. 126666

27. Z. Pan, F. Cao, X. Hu, X. Ji, A facile method for synthesizing $\mathrm{CuS}$ decorated $\mathrm{Ti}_{3} \mathrm{C}_{2}$ MXene with enhanced performance for asymmetric supercapacitors. J. Mater. Chem. A 7, 8984 (2019). https://doi.org/10.1039/C9TA00085B

28. R.M. Clark, J.C. Kotsakidis, B. Weber, K.J. Berean, B.J. Carey et al., Exfoliation of quasi-stratified $\mathrm{Bi}_{2} \mathrm{~S}_{3}$ crystals into micronscale ultrathin corrugated nanosheets. Chem. Mater. 28(24), 8942-8950 (2016). https://doi.org/10.1021/acs.chemmater. $6 \mathrm{~b} 03478$

29. F. Lu, R. Li, N. Yan Li, J. Yang. Huo et al., Improving the field-effect performance of $\mathrm{Bi}_{2} \mathrm{~S}_{3}$ single nanowires by an asymmetric device fabrication. ChemPhysChem (2015). https://doi.org/10.1002/cphc.201402594

30. J. Ni, Y. Zhao, T. Liu, H. Zheng, L. Gao et al., Strongly coupled $\mathrm{Bi}_{2} \mathrm{~S}_{3} @ \mathrm{CNT}$ hybrids for robust lithium storage. Adv. Energy Mater. 4, 1400798 (2014). https://doi.org/10.1002/ aenm. 201400798

31. T. Hurma, S. Kose, XRD Raman analysis and optical properties of CuS nanostructured film. Optik 127, 6000 (2016). https://doi.org/10.1016/j.ijleo.2016.04.019

32. S. Bera, A.K. Katiyar, A.K. Sinha, S.P. Mondal, S.K. Ray, Resistive switching characteristics of a single $\mathrm{Zn}$-doped $\mathrm{CuS}$ nanoball anchored with multi-walled carbon nanotubes. Mater. Design 101, 197-203 (2016). https://doi.org/10.1016/j.matdes. 2016.03.160

33. C. Hong, Y.I. Kim, J.H. Seo, J.H. Kim, A. Ma et al., Comprehensive study of the growth mechanism and photoelectrochemical activity of a $\mathrm{BiVO}_{4} / \mathrm{Bi}_{2} \mathrm{~S}_{3}$ nanowire composite. ACS Appl. Mater. Interfaces 12(35), 39713-39719 (2020). https:// doi.org/10.1021/acsami.0c07577 
34. L. Liu, M. Ikram, L. Ma, X. Zhang, H. Lv et al., Edge-exposed $\mathrm{MoS}_{2}$ nanospheres assembled with $\mathrm{SnS}_{2}$ nanosheet to boost $\mathrm{NO}_{2}$ gas sensing at room temperature. J. Hazard. Mater. 393, 122325 (2020). https://doi.org/10.1016/j.jhazmat.2020.122325

35. L. Meng, J. He, W. Tian, M. Wang, R. Long et al., Ni/Fe codoped $\mathrm{In}_{2} \mathrm{~S}_{3}$ nanosheet arrays boost photo-electrochemical performance of planar Si photocathodes. Adv. Energy Mater. 9, 1902135 (2019). https://doi.org/10.1002/aenm.201902135

36. Y. Guo, J. Yang, D. Wu, H. Bai, Z. Yang et al., Au nanoparticle-embedded, nitrogen-deficient hollow mesoporous carbon nitride spheres for nitrogen photofixation. J. Mater. Chem. A 8, 16218 (2020). https://doi.org/10.1039/D0TA03793A

37. W. Zheng, Y. Xu, L. Zheng, C. Yang, N. Pinna et al., $\mathrm{MoS}_{2}$ van der waals $\mathrm{p}-\mathrm{n}$ junctions enabling highly selective room-temperature $\mathrm{NO}_{2}$ sensor. Adv. Funct. Mater. 30, 2000435 (2020). https://doi.org/10.1002/adfm.202000435

38. S.Y. Cho, H.J. Koh, H.W. Yoo, J.S. Kim, H.T. Jung, Tunable volatile-organic-compound sensor by using Au nanoparticle incorporation on $\mathrm{MoS}_{2}$. ACS Sens. 2(1), 183-189 (2017). https://doi.org/10.1021/acssensors.6b00801

39. H. Liu, M. Li, O. Voznyy, L. Hu, Q. Fu et al., Physically flexible, rapid-response gas sensor based on colloidal quantum dot solids. Adv. Mater. 26, 2718-2724 (2014). https://doi.org/10. 1002/adma.201304366

40. Q. Sun, J. Wang, J. Hao, S. Zheng, P. Wan et al., $\mathrm{SnS}_{2} / \mathrm{SnS}$ p-n heterojunctions with an accumulation layer for ultrasensitive room-temperature $\mathrm{NO}_{2}$ detection. Nanoscale 11, 13741-13749 (2019). https://doi.org/10.1039/C9NR02780G

41. S. Cui, Z. Wen, X. Huang, J. Chang, J. Chen, Stabilizing $\mathrm{MoS}_{2}$ nanosheets through $\mathrm{SnO}_{2}$ nanocrystal decoration for highperformance gas sensing in air. Small 11, 2305-2313 (2015). https://doi.org/10.1002/smll.201402923
42. Z. Qin, C. Ouyang, J. Zhang, L. Wan, S. Wang et al., 2D WS nanosheets with $\mathrm{TiO}_{2}$ quantum dots decoration for high-performance ammonia gas sensing at room temperature. Sens. Actuators B: Chem. 253, 1034-1042 (2017). https://doi.org/ 10.1016/j.snb.2017.07.052

43. W.Y. Chen, X. Jiang, S.-N. Lai, D. Peroulis, L. Stanciu, Nanohybrids of a MXene and transition metal dichalcogenide for selective detection of volatile organic compounds. Nat. Commun. 11, 1302 (2020). https://doi.org/10.1038/ s41467-020-15092-4

44. K.M.B. Urs, N.K. Katiyar, R. Kumar, K. Biswas, A.K. Singh et al., Multi-component ( $\mathrm{Ag}-\mathrm{Au}-\mathrm{Cu}-\mathrm{Pd}-\mathrm{Pt})$ alloy nanoparticle-decorated p-type 2D-molybdenum disulfide $\left(\mathrm{MoS}_{2}\right)$ for enhanced hydrogen sensing. Nanoscale 12, 11830-11841 (2020). https://doi.org/10.1039/D0NR02177F

45. D. Fu, C. Zhu, X. Zhang, C. Li, Y. Chen, Two-dimensional net-like $\mathrm{SnO}_{2} / \mathrm{ZnO}$ heteronanostructures for high-performance $\mathrm{H}_{2} \mathrm{~S}$ gas sensor. J. Mater. Chem. A 4, 1390-1398 (2016). https://doi.org/10.1039/C5TA09190J

46. J. Hao, D. Zhang, Q. Sun, S. Zheng, J. Sun, Y. Wang, Hierarchical $\mathrm{SnS}_{2} / \mathrm{SnO}_{2}$ nanoheterojunctions with increased activesites and charge transfer for ultrasensitive $\mathrm{NO}_{2}$ detection. Nanoscale 10, 7210-7217 (2018). https://doi.org/10.1039/ C8NR01379A

47. J.V. Vaghasiya, C.C.M. Martinez, J. Vyskočil, Z. Sofer, M. Pumera, Integrated Biomonitoring Sensing with Wearable Asymmetric Supercapacitors Based on $\mathrm{Ti}_{3} \mathrm{C}_{2}$ MXene and 1T-Phase $\mathrm{WS}_{2}$ Nanosheets. Adv. Funct. Mater. 30, 2003673 (2020). https://doi.org/10.1002/adfm.202003673 